\title{
DR. M. V. S. RAJU AND HIS STUDY OF LEAFY SPURGE IN SASKATCHEWAN
}

Research into the growth and development of leafy spurge, a common perennial weed which causes considerable crop loss and is toxic to young livestock, is under way at the University of Saskatchewan, Regina.

Dr. Raju is using a growth chamber to study individually and in total the effect on the weed of such environmental factors as light, humidity and temperature. Growth chambers are highly useful not only to simulate natural conditions but also to conduct controlled studies of environmental factors.

Light, for example, can be applied at various intensities while other factors are kept constant and the effect on the plant of different light levels can be determined. Dr. Raju says he hopes through experiments of this kind to find out how leafy spurge grows and then how to control its growth. He feels that the main problem with leafy spurge is its regenerative capacity. "Even a small piece of root can regenerate into a new plant. Fragments from any depth can develop into new plants and consequently the conventional method of deep tillage is of no use as a control. It is this capacity of roots for regeneration that makes the weed compete with crop plants and other vegetation, and resistant to the commonly used herbicides."

The growth chamber can be used for controlled studies of the effects of chemicals on the development of leafy spurge. This might lead to the discovery of a chemical that could control the regenerative capacity of the weed. Dr. Raju says that growth chambers are becoming increasingly popular in universities and research institutes and have several advantages over greenhouses for experimental studies. They are more efficient than greenhouses and can control several environmental variables. He added that, among other things, they are used to keep plants growing continuously to find out the

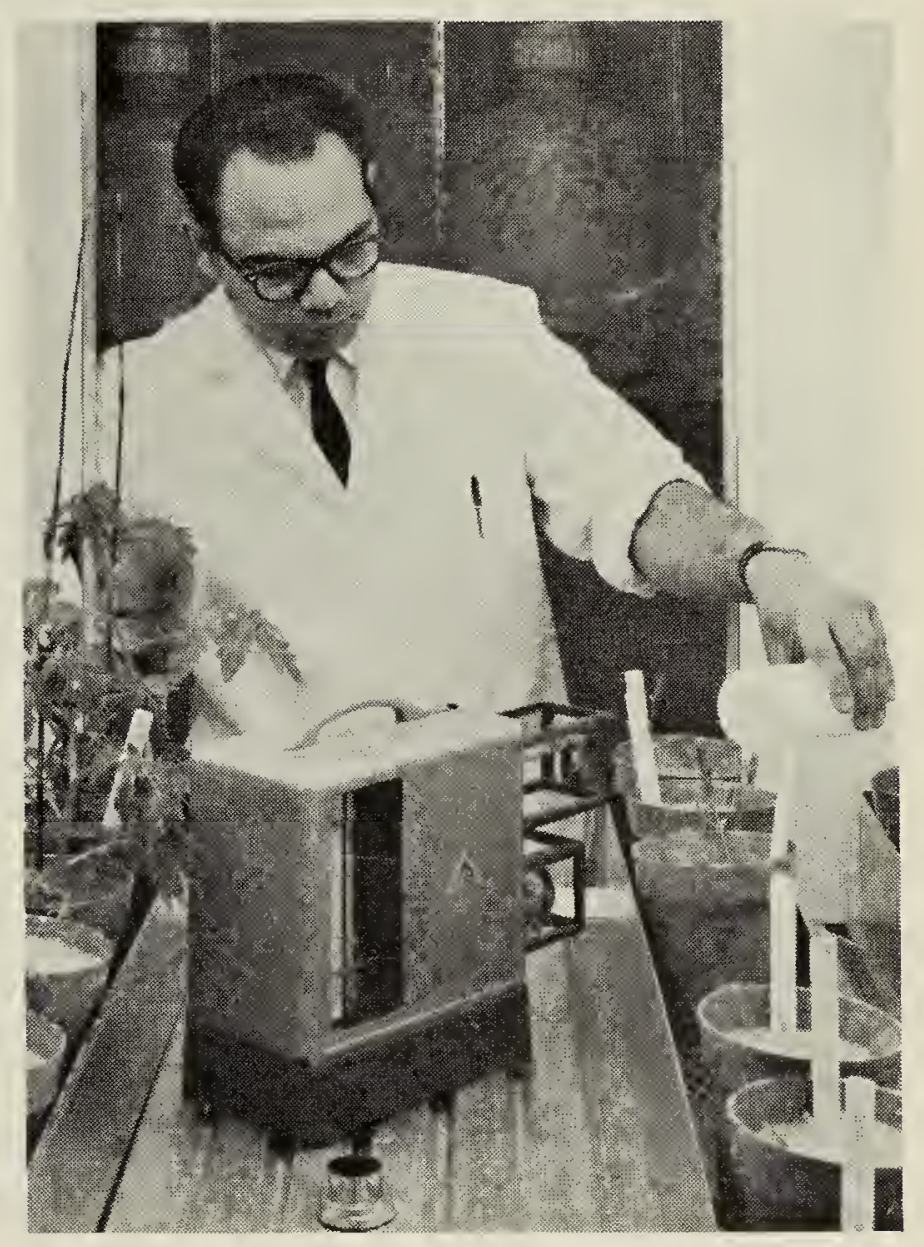

Photo by Robert R. Taylor

Dr. Raju pours a nutrient solution on plants in a growth chamber. The instrument in the foreground is for recording temperature and relative humidity.

nutritional and other environmental requirements for proper growth and to produce better plants.

Dr. Raju, a specialist in the anatomy and morphology of vascular plants, came to Regina in 1964 as assistant professor in biology. Previously he worked as a post-doctoral fellow at the University in Saskatoon and while there he began his research on leafy spurge. Dr. Raju is a native of India, where he received his early education. He has his bachelor and master of science degree from the University of Mysore, Bangalore, India, and his doctor of philosophy degree from Washington University, St. Louis, Missouri.

Editor's Note: We are pleased to give credit to the Western Producer (October 20, 1966) for the above article and photo. 